\title{
A TEORIA DA METÁFORA CONCEPTUAL EM AÇÃO
}

\author{
Morgana de Abreu Leal é professora de Inglês no ensino fundamental, médio e em curso de idiomas livre, e mestranda do curso de \\ Letras na UERJ. \\ E-mail: morganabrleal@gmail.com \\ Robson Cavaca de Abreu é professor de Inglês no ensino fundamental e em curso de idiomas livre, e mestrando do curso de Letras \\ na UERJ. \\ E-mail: mr.robsonabreu@gmail.com
}

Resumo

Este artigo argumenta como a Teoria da Metáfora Conceptual (ALMEIDA et al., 2010; EVANS \& GREEN, 2006; etc.) pode auxiliar no processo de ensino-aprendizagem de inglês (KÖVECSES, 2010) e mostra algumas práticas pedagógicas (LAZAR, 2003) que contribuem para colocar a teoria em ação.

\begin{abstract}
This article argues how the Conceptual Metaphor Theory (ALMEIDA et al., 2010; EVANS \& GREEN, 2006; etc.) may help the process of teaching-learning English (KÖVECSES, 2010) and shows some pedagogical practices (LAZAR, 2003) that contribute to put theory into action.
\end{abstract}

\section{1) INTRODUÇÃOO}

A Teoria da Metáfora Conceptual foi proposta por George Lakoff e Mark Johnson em seu livro Metaphors We Live By, de 1980. Sua premissa básica é a de que a metáfora não é mero recurso estilístico, mas uma maneira de conceptualizar a própria experiência humana. Neste artigo apresentaremos os conceitos inerentes à metáfora conceptual sob a ótica de diferentes e complementares autores (ALMEIDA et al., 2010; KÖVECSES, 2010; EVANS \& GREEN, 2006), para então discutirmos o que são expressões idiomáticas à luz da Linguística Cognitiva. Defenderemos, junto com Kövecses, uma invasão das premissas da Teoria da Metáfora Conceptual no ensino/aprendizagem de língua inglesa para responder à seguinte questão: como esses princípios podem auxiliar a aquisição de vocabulário de uma língua estrangeira? Em seguida, apresentaremos um material suplementar, o livro Meanings and Metaphors (LAZAR, 2003), que se propõe a ensinar léxico da linguagem figurativa. Por último, avaliaremos algumas atividades propostas por esse livro à luz do que propõe Kövecses (2010) para o ensino-aprendizagem de língua estrangeira. Ou seja, colocaremos a Teoria da Metáfora Conceptual em ação.

\section{2) METÁFORAS CONCEPTUAIS: APRESENTAÇÃO DOS CONCEITOS}

Apresentamos aqui as diferenças entre o conceito tradicional de metáfora e o de metáfora conceptual (cf. ALMEIDA et al., 2010, p. 33-36). O conceito de metáfora 
como figura de linguagem não é nenhuma novidade. Inicialmente, a metáfora literária é um recurso expressivo e de estilo utilizado, sobretudo, nos textos literários. Lakoff (2006, p. 185) afirma que teóricos clássicos desde Aristóteles consideram a metáfora como o uso de linguagem comum com significado deslocado, diferente daquele do diaa-dia, para expressar conceitos "similares".

Ribeiro (2007, p. 346) explica que na metáfora ocorre "o emprego de um vocábulo fora de seu significado básico, em virtude de uma semelhança”. A metáfora é considerada uma comparação sem elementos linguísticos comparativos (ibidem). Observe, por exemplo, os versos do poema Fogo e Metal: "coberto por um cabelo flamejante/labaredas explodem na extensão de cada fio" (COSTA, 2011). O "cabelo" da musa inspiradora é comparado ao fogo provavelmente por causa de sua cor vermelha. Sabemos que "labaredas" não explodem em fios de cabelo; essas imagens que podemos perceber no poema, de acordo com a explicação de metáfora clássica, são recursos linguísticos de estilo, utilizados para "embelezar" a linguagem e para expressar novas imagens e significados em textos literários.

Com os estudos das Ciências Cognitivas, em especial da Linguística Cognitiva (doravante LC), surge a Teoria da Metáfora Conceptual (doravante TMC). A LC, por sua vez, vê a metáfora como processo cognitivo. Veja o exemplo:

Nosso relacionamento chegou a uma encruzilhada.

Observe como em (1) o relacionamento pode ser concebido como um viajante que encontrou um obstáculo (EVANS \& GREEN, 2006, p. 295). De acordo com Almeida et al. (2010, p. 35), a metáfora permite conceber e imprimir ideias abstratas, desempenhando um papel de destaque para o sistema conceptual humano. Podemos conceptualizar dois domínios conceptuais (amor e viagem), aproximá-los, e conceber um como outro (AMOR É UMA VIAGEM) ${ }^{\mathrm{i}}$. Faz-se necessária uma breve interrupção para explicarmos o conceito de domínio conceptual. De acordo com Miranda (2009, p. 8286), domínios conceptuais são conjuntos de conhecimentos prévios e estruturados, social e culturalmente produzidos, relativamente estáveis e que podem ser identificados e evocados em eventos discursivos, e são flexíveis conforme as necessidades da instanciação. Retornando ao assunto "metáfora conceptual", quando observamos um link metafórico entre dois domínios, a ele chamamos mapeamento - ou mapping em inglês (LAKOFF, 2006, p. 190). A metáfora para a LC é, então, uma propriedade do pensamento: "entende-se que as expressões linguísticas metafóricas são o reflexo visível de um mecanismo cognitivo que consiste em estabelecer uma vinculação conceptual entre domínios distintos." (ALMEIDA et al., 2010, p. 34). Essa visão das expressões metafóricas admite, necessariamente, que a metáfora está no uso comum da linguagem, e não é recurso poético apenas. 
No exemplo (1), podemos verificar que há dois domínios conceptuais, amor e viagem. Eles têm nomes especiais: domínio-fonte e domínio-alvo. Veja o que afirma Kövecses:

o domínio conceptual no qual encontramos as expressões [linguísticas] metafóricas para entender outro domínio conceptual se chama domínio-fonte, enquanto o domínio conceptual que é entendido dessa maneira se chama domínio-alvo. ${ }^{\mathrm{ii}}$ (KÖVECSES, 2010, p. 4, tradução nossa, grifos do autor).

O domínio-alvo é AMOR, enquanto o domínio-fonte é VIAGEM; a expressão linguística metafórica é relacionamento chegou a uma encruzilhada e a metáfora conceptual é O AMOR É UMA VIAGEM. Na estrutura de evento metafórico, podemos dizer que "relacionamento" representa um papel de "viajante" dentro da "viagem".

Kövecses também afirma que as metáforas conceptuais geralmente utilizam um conceito mais abstrato no domínio-fonte e um mais concreto e físico no domínio-alvo. Para ele, "as nossas experiências com o mundo físico servem de fundamentação natural e lógica para a compreensão de domínios mais abstratos",iii (KÖVECSES, 2010, p. 7, tradução nossa).

Kövecses (2010), após uma ampla pesquisa, descobriu que os domínios-fonte mais comuns no mapeamento metafórico são relacionados ao CORPO HUMANO, ANIMAIS, PLANTAS, COMIDAS e FORÇA, e os domínios-alvo mais comuns incluem categorias conceptuais como EMOÇÃO, MORALIDADE, PENSAMENTO, RELAÇÕES HUMANAS e TEMPO. Essa afirmação tem duas implicações. Uma delas é a motivação - em oposição à arbitrariedade - da metáfora conceptual. Segundo Evans \& Green (2006, p. 298, tradução nossa), "conceitos-alvo tendem a ser mais abstratos, carentes de características físicas e por isso mais difíceis de entender e falar a respeito [...] domínios-fonte tendem a ser mais concretos e por isso mais imediatamente perceptíveis"iv . Kövecses assume, assim, que as metáforas conceptuais estão baseadas em experiências humanas corporificadas.

Bernardo (2009) corrobora com a hipótese da corporificação do significado:

$\mathrm{Na}$ abordagem sociocognitiva, a capacidade linguística não é entendida como um componente autônomo em relação a outras habilidades cognitivas. O significado linguístico é corporificado; surge a partir da capacidade biológica e das experiências físicas e socioculturais captadas do meio ambiente. Nesse sentido, é possível estudar o significado pragmático como parte do aparato cognitivo envolvido na conceptualização e não externo a ele, já que o significado social se desenvolve internamente a partir de modelos e processos cognitivos particulares dos seres humanos. (BERNARDO, 2009, p. 1106).

Outra implicação é a unidirecionalidade da metáfora conceptual: domínios fonte e alvo não são reversíveis. Mesmo quando as metáforas conceptuais parecem 
bidirecionais, como PESSOAS SÃO MÁQUINAS e MÁQUINAS SÃO PESSOAS, na verdade são unidirecionais. Veja os exemplos:

\section{Pedro é uma calculadora humana.}

Meu computador tem vida própria.

Note como, no exemplo (2), os atributos mecânicos e funcionais são mapeados nas pessoas, enquanto no exemplo (3) é a noção de desejo e volição que é mapeada na máquina. Isso mostra que cada metáfora conceptual é distinta em sua natureza, porque ela conta com mapeamentos diferentes (cf. EVANS \& GREEN, 2006).

Somado aos mapeamentos, as estruturas metafóricas carregam consigo conhecimento detalhado. Isso porque aspectos não explícitos dos domínios podem ser inferidos no uso da metáfora conceptual. Veja o exemplo retirado de Evans \& Green (2006, p. 299), cuja metáfora conceptual é O ARGUMENTO É UMA VIAGEM:

Eu me perdi no argumento.

Observe como mapeamentos implícitos do domínio-fonte podem ser inferidos: PARTICIPANTES correspondem a VIAJANTES, o ARGUMENTO corresponde a uma VIAGEM, etc. Como no domínio-fonte, os viajantes podem se perder, podem não chegar ao destino, etc. A associação entre fonte e alvo dá origem à implicatura (uma rica inferência) de que esses eventos também podem ocorrer no domínio-alvo ARGUMENTO.

Outro conceito relevante para a TMC é o de esquemas imagéticos. Segundo Pina,

Os esquemas imagéticos são estruturas abstratas e genéricas advindas de experiências sensório-motoras, facultadas pelas características da espécie humana. Essas imagens esquemáticas são de natureza cinestésica, pois dizem respeito a muitos aspectos da atividade do ser humano no espaço, tais como: orientação, movimento, equilíbrio, forma etc. Os esquemas imagéticos mais comuns refletem as experiências de percurso, continente/conteúdo, parte/todo, ligação, centro/periferia, em cima/embaixo, frente/trás, entre outros. (PINA, 2005, p. 1).

A consequência disso para a TMC é que o "pensamento abstrato e o raciocínio, facilitados pela metáfora, são vistos como tendo um esquema imagético e, logo, uma base corporificada" " (EVANS \& GREEN, 2006, p. 301, tradução nossa). Conceptualizamos, por exemplo, o esquema de percurso, que pressupõe uma ida de um lugar para outro (origem, alvo, distância percorrida), baseado na experiência física diária de nos deslocar. Se observarmos o exemplo (1), podemos notar que esse esquema imagético de percurso está presente naquela conceptualização. 
Foi necessário introduzir as características principais da TMC para então apresentar o assunto que nos interessa nesse artigo: como essa teoria pode ajudar no ensino/aprendizagem da língua inglesa? ${ }^{\mathrm{vi}}$

\section{3) EXPRESSÕES IDIOMÁTICAS À LUZ DA TMC}

Vamos começar pelo que Kövecses (2010, p. 231-234) argumenta sobre as expressões idiomáticas. Na visão tradicional, elas são manifestações puramente linguísticas. Podem ser metáforas, metonímias, pares de palavras, símiles, ditados populares, verbos preposicionais, etc. Similares a palavras, expressões idiomáticas apenas têm propriedades sintáticas e um significado inerente a suas partes. Já na visão da LC, expressões idiomáticas são produtos de nosso sistema conceptual.

Uma expressão idiomática não é somente uma expressão que tem um significado que é de alguma maneira especial em relação aos significados das partes que a constituem, mas sim surge do nosso conhecimento de mundo mais geral incorporado no nosso sistema conceptual. Em outras palavras, expressões idiomáticas (ou, pelo menos, a maioria delas) são conceptuais, e não linguísticas, por natureza. ${ }^{\text {vii }}$ (KÖVECSES, 2010, p. 233, tradução nossa).

O autor argumenta, ainda, que o significado das expressões idiomáticas é, muitas vezes, motivado e não arbitrário. Algumas expressões, como kick the bucket (literalmente, chutar o balde, mas que significa, na verdade, morrer) são exclusivamente arbitrárias, mas a maioria das expressões tem significado motivado, como spit fire, que significa cuspir fogo, uma expressão da metáfora conceptual RAIVA É FOGO. Nesse caso, raiva é compreendida via metáfora conceptual.

Mas por que cuspir fogo tem um significado mais intenso do que estar com raiva? Kövecses (2010, p. 238) explica que o que determina o significado de uma expressão idiomática é o domínio-alvo da metáfora conceptual à qual ela está relacionada. Nesse caso, o significado de cuspir fogo depende da existência da metáfora RAIVA É FOGO. O significado geral tem a ver com raiva, mas o significado mais preciso, que é estar com muita raiva, depende do mapeamento da metáfora conceptual "intensidade do fogo é intensidade da raiva". Podemos concluir, portanto, que os mapeamentos das metáforas conceptuais ajudam a explicar os seus significados.

\section{4) COMO A TMC PODE AUXILIAR O PROCESSO DE ENSINO- APRENDIZAGEM DE LÍNGUA ESTRANGEIRA: PROPOSTAS DE KÖVECSES (2010)}

Sendo, então, a conceptualização metafórica um poderoso recurso discursivo, podemos estender esse conceito à fluência metafórica e à competência metafórica. No ensino de uma língua estrangeira, aprendizes podem se beneficiar desses conceitos 
trazidos pela LC. Conscientizando os alunos sobre a metáfora conceptual, damos a eles a chance de entender a motivação metafórica da expressão, ao invés de simplesmente memorizar o item a ser aprendido, facilitando o processo de aquisição e retenção de vocabulário (KÖVECSES, 2010, p. 238). Mas essa é apenas uma das implicações pedagógicas e benefícios da TMC.

Kövecses (2010, p. 239) cita estudos que indicam o impacto da conscientização da metáfora conceptual sobre a velocidade e a profundidade na aquisição de vocabulário do aprendiz. Um dos benefícios é a aceleração da absorção de vocabulário. Como professores, não podemos confiar na absorção incidental de vocabulário, temos que fornecer meios de chamar a atenção dos aprendizes para itens lexicais e estimular o armazenamento desses na memória de longo prazo. Uma maneira de realizar isso é através de atividades que envolvam elaboração.

Elaboração é uma gama de operações mentais que envolvem um esforço cognitivo maior, como associar itens lexicais do mesmo campo semântico a imagens mentais, compará-los com itens lexicais da língua materna, etc. A operação de associar itens lexicais a imagens mentais se chama codificação dupla (dual coding) e, segundo Kövecses (2010, p. 239), esse tipo de elaboração é especialmente benéfica ao aprendiz, porque, além de a imagem mental servir como caminho para relembrar o item, ela "conscientiza o aluno dos domínios-alvo concretos ou contextos nos quais certas palavras ou expressões foram originalmente usadas em seus sentidos literais (e por isso facilmente 'imagináveis')"viii (ibidem, tradução nossa). Fazer associações entre significado e imagens pode ajudar a reconhecer o sentido figurativo da expressão em questão em ocorrências futuras, e a, também, lembrar-se do significado para poder fazer uso em seu discurso.

Outra maneira de estimular a elaboração é apresentar ao aprendiz atividades nas quais se selecione, organize e apresente vocabulário de modo a aumentar a conscientização sobre metáforas conceptuais. Um exemplo de atividade envolve agrupar e/ou categorizar expressões idiomáticas de acordo com as metáforas ou domínios-fonte às quais pertencem. Vocabulários apresentados em grupos, em vez de expressões aleatórias, são mais fáceis de aprender e facilitam a retenção por mais tempo. E para aumentar as chances de melhorar a absorção de vocabulário, deve-se sempre somar novo conhecimento ao que o aluno já possua (cf. KÖVECSES, 2010, p. 241).

A conscientização sobre metáforas conceptuais promove a compreensão mais profunda do significado do uso figurativo de palavras e expressões. Kövecses (2010, p. 242) enumera, ainda, três vantagens adicionais de se incorporar a metáfora conceptual ao ensino de línguas: (i) a dimensão avaliativa do sentido no uso das expressões idiomáticas; (ii) as restrições desse uso; (iii) a conexão entre essas expressões e a cultura e a história daquela comunidade linguística. 


\section{5) A MATERIALIZAÇÃO DA TMC: ANÁlISE DE ATIVIDADES DO LIVRO MEANINGS AND METAPHORS}

\section{1) SOBRE O LIVRO}

O livro Meanings and Metaphors (LAZAR, 2003) é um material suplementar para o ensino de língua inglesa, destinado a adolescentes e adultos, de nível baixointermediário a avançado, que se propõe a explorar e praticar linguagem figurativa na língua-alvo. Ele é composto de 34 unidades, de tópicos diferentes e atividades fotocopiáveis, e também de instruções para o professor. As atividades vão de brainstorming sobre determinada metáfora conceptual a escrever um poema para praticar o uso poético da linguagem figurativa.

A introdução do livro nos informa que o objetivo dele é explorar e praticar vocabulário ligado à linguagem figurativa, como expressões idiomáticas, metáforas, metonímias, símiles etc. Há uma explicação sobre metáforas, e até mesmo um glossário de termos, mas não fica claro para o leitor se estão partindo do conceito de metáfora da LC.

O autor dá três razões para o ensino de linguagem figurativa nas aulas de inglês como língua estrangeira: (i) pode ser uma maneira eficaz de expandir o vocabulário do aprendiz; (ii) a linguagem figurativa proporciona uma maneira prática de organizar o vocabulário a ser aprendido; (iii) as atividades do livro proporcionam um ponto de partida para integrar as quatro habilidades linguísticas. Além disso, as atividades proporcionam uma oportunidade para refletir sobre o caráter cultural da língua (LAZAR, 2003, p. 1-2).

Até aqui, pudemos observar como o material suplementar teoriza a sua prática. A seguir, vamos analisar se as atividades propostas pelo livro estão de acordo com os princípios da TMC e com o que Kövecses preconiza como contribuição da teoria para a prática pedagógica. Para tal, comentaremos como a atividade apresenta a metáfora que será trabalhada e avaliaremos de que maneira a prática pedagógica realiza as propostas de Kövecses (2010) para que a metáfora conceptual possa auxiliar no processo de ensino-aprendizagem de inglês como língua estrangeira.

\section{2) ANÁLISE DE ATIVIDADES}

Já na primeira unidade observamos exemplos do que Kövecses (2010) sugere para as práticas pedagógicas inseridas na TMC. 
3 In the chart below are some words from the texts in 2. Match each word with both its literal and its metaphorical meaning.

\begin{tabular}{|c|c|c|}
\hline Words & Literal meanings & Metaphorical meanings \\
\hline $\begin{array}{l}\text { path (Text A) } \\
\text { diet (Text B) } \\
\text { flavour (Text B) } \\
\text { oasis (Text C) } \\
\text { magnet (Text E) }\end{array}$ & $\begin{array}{l}\text { a place in a desert where there is water } \\
\text { and plants grow } \\
\text { the particular taste of a food or drink } \\
\text { a track that people walk along, sometimes } \\
\text { covered with concrete, etc. } \\
\text { a piece of iron or steel which attracts } \\
\text { other metal objects towards it } \\
\text { the kind of food and drink that somebody } \\
\text { eats regularly }\end{array}$ & $\begin{array}{l}\text { a person or place that attracts many other } \\
\text { people or things because it is so interesting } \\
\text { the particular quality of something that makes } \\
\text { it what it is } \\
\text { too much of something which you think is } \\
\text { boring or unpleasant } \\
\text { a set of actions, which lead to a particular goal } \\
\text { a pleasant, peaceful place surrounded by } \\
\text { something unpleasant or noisy }\end{array}$ \\
\hline
\end{tabular}

Figura 1: Meanings and Metaphors, U. 1, p. 7 ( CUP

Podemos notar como a atividade estimula o aluno a relacionar os significados literais e metafóricos dos itens lexicais. Para facilitar, as palavras estão contextualizadas em textos. Esse exercício será feito após outras atividades que apresentaram conceitos de linguagem figurativa (mais especificamente metáfora e símile) e exemplos de gêneros textuais e suas respectivas fontes. Esses textos são então utilizados para a atividade recortada acima. Essa atividade é elaborada e exige um certo esforço cognitivo e a habilidade de relacionar diferentes significados ao mesmo item lexical, portanto, cumpre o que Kövecses (2010) sugere como uma atividade capaz de fornecer meios para a aquisição e absorção de vocabulário.

Observe a seguir a figura 2: a atividade 1 da segunda unidade, intitulada The heart of the matter: Parts of the body. A atividade introduz significados metafóricos relacionados a partes do corpo. Depois, os aprendizes têm o insumo de expressões idiomáticas, mas eles terão que utilizar as "dicas" que obtiveram na atividade 1 para compreender as expressões da atividade 2 e resolvê-las (figura 3). A atividade está em harmonia com a TMC e com as propostas de Kövecses (2010) por vários motivos: ela conscientiza sobre um domínio-fonte comumente utilizado na nossa comunicação diária e sobre a hipótese da corporificação do significado, além de relacionar imagem e significado (codificação dupla), o que facilita o aprendizado e a retenção de vocabulário.

Sobre a hipótese de que o significado linguístico é corporificado, ou seja, é construído na experiência física e sociocultural do ser humano, devemos salientar a sua especial importância para o ensino-aprendizagem de línguas. Como o significado de certas expressões linguísticas está diretamente relacionado ao seu uso pragmático e à cultura da língua-alvo, pode-se argumentar que ensinar essas "relações corporificadas" entre expressão linguística e significado facilita a compreensão e aquisição de línguas, sobretudo a estrangeira. 
1 Look at the picture and read the ideas about the parts of the body. Do you agree with them? Add any ideas of your own.

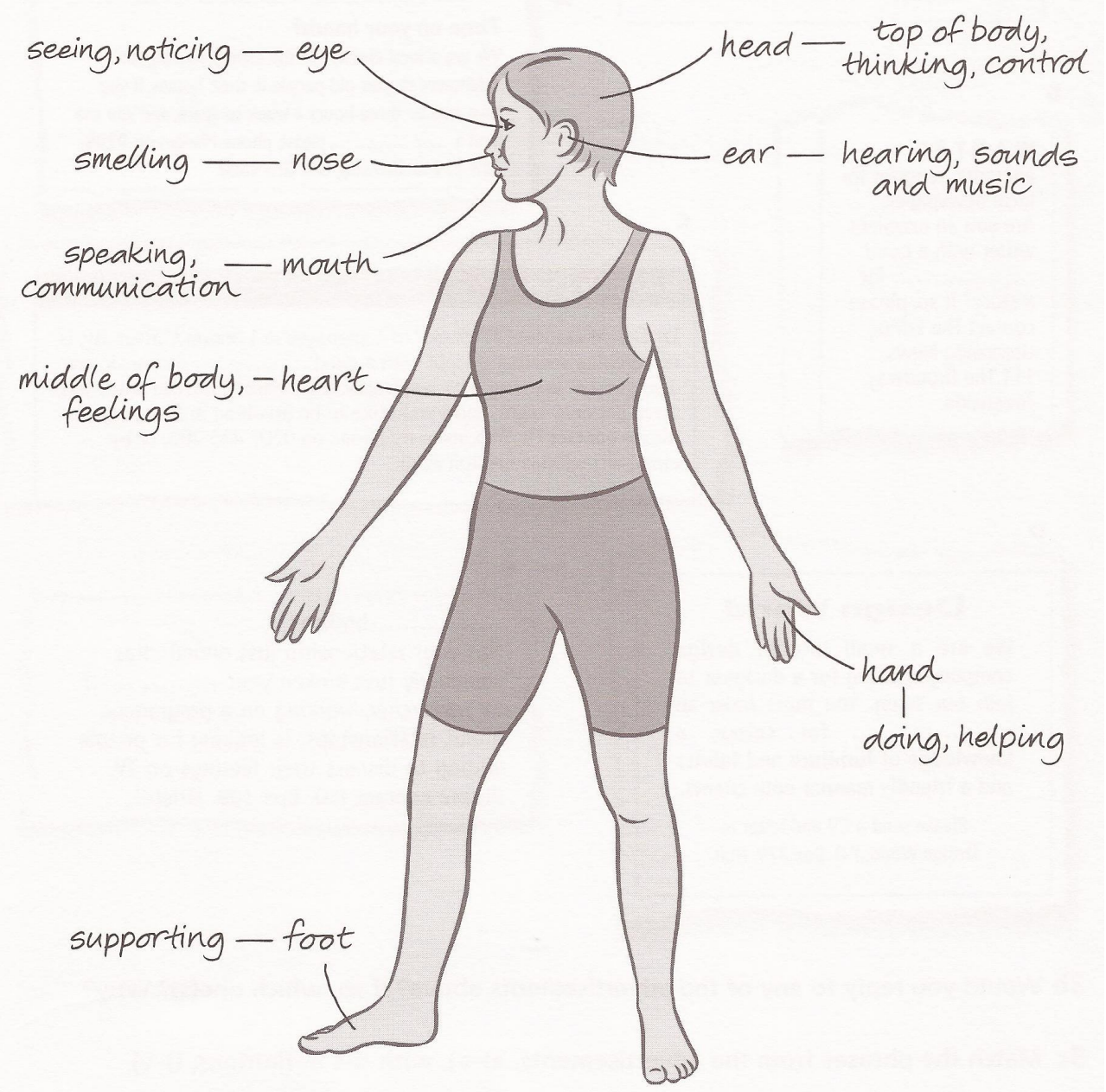

Figura 2: Meanings and Metaphors, U. 2, p. 9 (C) CUP

2a Discuss these questions with a partner, and write short notes for the answers.

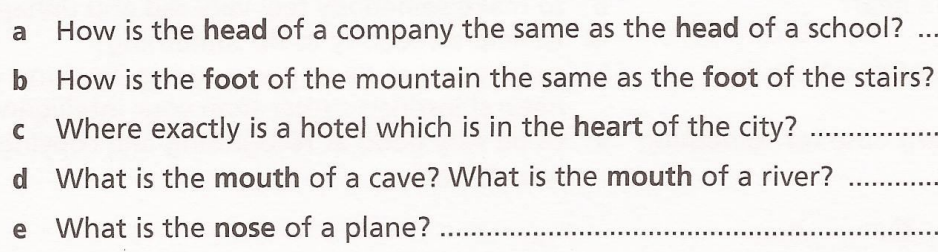

Figura 3: Meanings and Metaphors, U. 2, p. 9 @ CUP

Já no exercício 3A da mesma Unidade 2 (figura 4), o aluno usa ideias e associações do exercício 1 para estabelecer os significados metafóricos para as expressões que encontrará em $3 \mathrm{~A}$, quando terá que inserir as partes do corpo nas expressões encontradas nos "classificados" da atividade. Essa atividade está alinhada 
com o que preconiza Kövecses (2010), já que permite que o aprendiz se conscientize sobre os diversos significados que podem ser atribuídos aos itens e que amplie o seu vocabulário ao correlacionar diferentes sentidos para as metáforas, o que, por sua vez, auxiliará a sua memória de longo prazo e o uso dessas expressões em seu discurso.

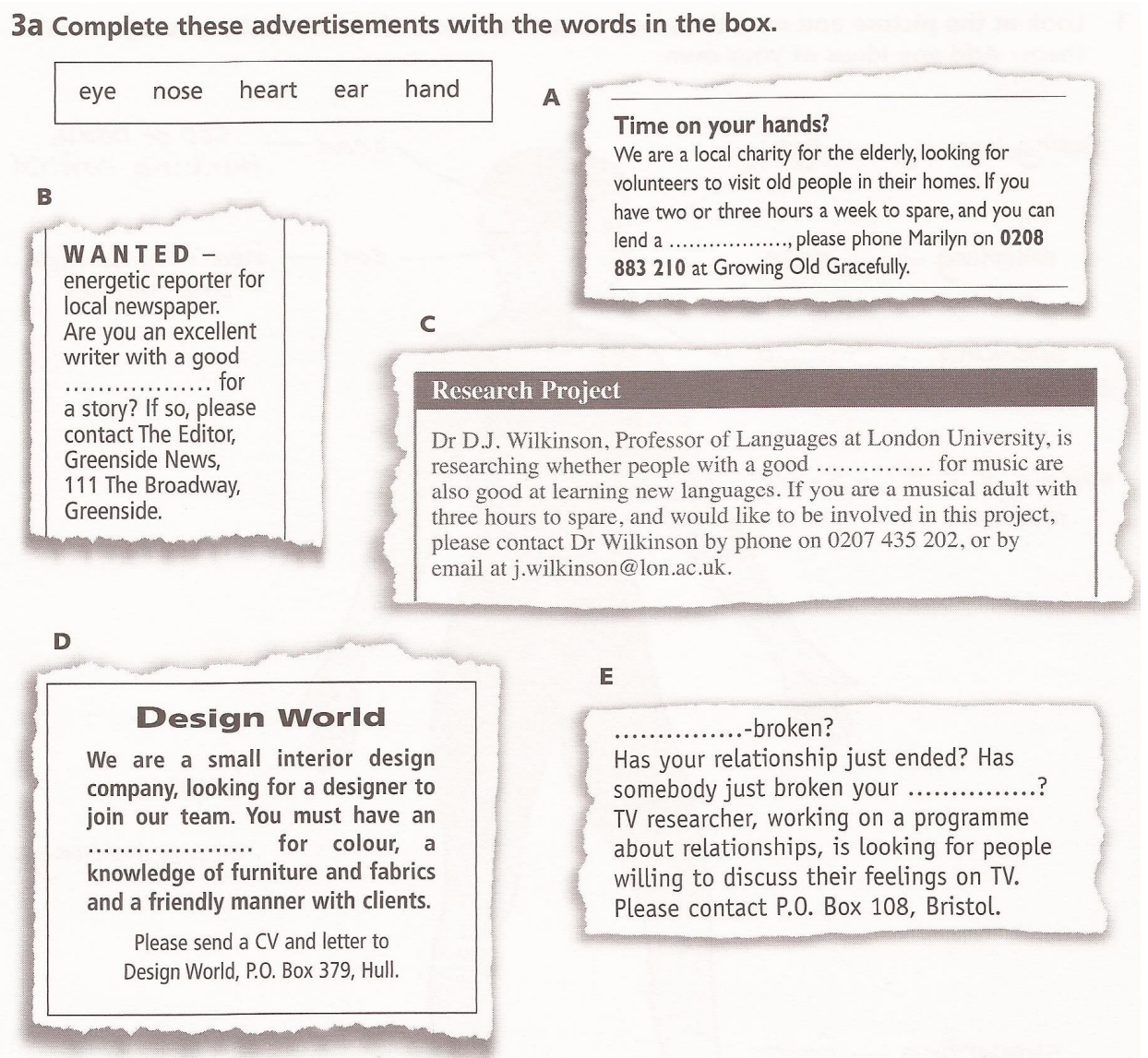

Figura 4: Meanings and Metaphors, U. 2, p. 10 @ CUP

Observe agora a atividade 4 da unidade 5 (figura 5). Após as atividades que proporcionam a prática de metáforas sobre o clima, o aluno é estimulado a criar contextos de uso para as expressões metafóricas. Depois, ele é estimulado a relacionálas com a sua língua materna.

Quando o aprendiz realiza atividades que o estimulem a um esforço cognitivo maior, como na atividade abaixo, ele aprende também contextos de uso de determinadas expressões (o que chamamos de collocations, ou seja, palavras que se combinam para formar expressões comuns em determinada língua, como, por exemplo, dizemos sempre a quick meal - uma refeição rápida - e nunca a fast meal, apesar de os dois adjetivos significarem "rápida"). E como essas expressões podem ser metáforas conceptuais, reafirmamos a importância de se conscientizar os aprendizes sobre as metáforas presentes na comunicação diária. Outro benefício é que, quando o aluno produzir 
linguagem, soará mais natural e será compreendido mais facilmente pelo seu interlocutor, auxiliando o aluno a alcançar a competência linguística.

4 Choose one of the following and either act it out for other students or write a short conversation to illustrate it. The other students guess which one you have chosen.
a a sunny smile
b a warm welcome
c a frosty look
d a frosty reception
e an icy look
f a breezy manner
g a stormy relationship

Figura 5: Meanings and Metaphors, U. 5, p. 22 (C) CUP

2a Put sentences a)- $\mathrm{m}$ ) into the correct categories in the chart below.

a I was very touched that my cousin sent me some flowers when I was in hospital.

b Her daughters suggested that she go to the party because they felt it might cheer her up.

c When I suggested going out for lunch, I only got a lukewarm response from her.

d The way he behaved is a big slap in the face after everything l've done for him.

e It makes my blood boil to think of my mother slaving away in that filthy factory all day.

f She laughed loudly, still on a high from the morning's good news.

g Unfortunately, Bill is a very hot-tempered man who often gets into arguments.

h I felt really down when I got back from my holiday.

i He gave me a smile which just melted my heart.

j The horrible story sent a chill down his spine, and he couldn't sleep that night.

k 'What he said really hit me - I felt awful!' my aunt said.

I I am always exhausted, and feel very low, so my mother says I should go to the doctor.

$\mathrm{m}$ Claire really thought she was going to get the job as manager, so it was a terrible blow when she didn't.

Feelings are ...

'Up' and 'down' Physical contact

Figura 6: Meanings and Metaphors, U. 9, p. 33 (C) CUP

Revista Escrita

Rua M arquês de São Vicente, 225 Gávea/RJ CEP 22453-900 Brasil

Ano 2011. Número 13. ISSN 1679-6888.

escrita@puc-rio.br 
Por fim, observe a atividade da unidade 9 (figura 6, acima). O aluno é estimulado a categorizar as expressões de acordo com os seus domínios-fonte, nas metáforas conceptuais SENTIMENTOS SÃO CONTATO FÍSICO, SENTIMENTOS SÃO TEMPERATURA e SENTIMENTOS SÃO ALTURA. Essa atividade trabalha com a metáfora conceptual como preconiza a LC, e, ao mesmo tempo, está de acordo com as sugestões de Kövecses (2010) descritas na seção 4: provoca a elaboração ao solicitar que o próprio aluno agrupe informações, soma novo conhecimento ao que o aluno já possui, associa significados e imagens, fornece meios para a codificação dupla. Práticas pedagógicas que aumentam a conscientização sobre metáforas conceptuais e que apresentam vocabulário em grupos, ao invés de expressões aleatórias, facilitam a aquisição e retenção do vocabulário apresentado e o processo de ensino-aprendizagem, porque ajudam o aluno a inferir significados, fornecem ao aprendiz caminhos para relembrar os itens e também porque o auxiliam a reconhecer sentidos figurativos de expressões da língua-alvo.

\section{6) CONCLUSÃO}

Nesse artigo, pudemos vislumbrar como a conscientização sobre as metáforas conceptuais, por serem realizações pragmáticas da língua, pode auxiliar o processo de ensino-aprendizagem do inglês como língua estrangeira. Certos aspectos da TMC, como domínios conceptuais, mapeamentos, esquemas imagéticos e corporificação do significado, ao serem evidenciados na prática pedagógica em sala de aula, facilitam a aquisição e retenção de vocabulário da língua-alvo, bem como medeiam a construção de significados no uso da língua-alvo. Como já discutido anteriormente, o significado é coconstruído socioculturalmente, e por isso se faz importante o ensino-aprendizagem de metáforas conceptuais, já que elas são realizações sócio-pragmáticas de modelos e processos cognitivos humanos.

Após uma breve análise de algumas atividades presentes no livro Meanings and Metaphors (LAZAR, 2003), vimos que elas oferecem oportunidades de aprendizagem, pois envolvem elaboração, uma gama de operações mentais de esforço cognitivo maior. Por isso, podemos reafirmar que, apesar de o material complementar não estar declaradamente comprometido com os princípios da LC e da TMC, a maneira como o livro aborda o que a LC chama de metáforas conceptuais auxilia o processo de ensinoaprendizagem da língua inglesa, visto que o "raciocínio metafórico", tal qual recomendado pela TMC e por Kövecses (2010), é estimulado nas atividades do livro.

Além do já exposto, devemos retomar o que Kövecses (2010) declara como vantagens de se incorporar a metáfora conceptual ao ensino de línguas: compreende-se mais profundamente o significado do uso figurativo de palavras e expressões; permite avaliar se o uso de certa expressão está adequado à situação comunicativa; entende-se 
melhor a relação entre língua e o momento sociocultural. Essas "vantagens" estão presentes nas atividades do livro Meanings and Metaphors (LAZAR, 2003). Relembre, por exemplo, a análise da figura 2 e 3: essas atividades conscientizam o aprendiz sobre metáforas conceptuais comumente utilizadas na nossa comunicação diária atual, bem como sobre os diversos sentidos dessas metáforas, cumprindo, então, o que Kövecses (2010) preconiza.

Nesse artigo, pudemos reconhecer, superficialmente, como a TMC contribui para o processo de ensino-aprendizagem de línguas. Esperamos que, futuramente, surjam discussões mais aprofundadas sobre o papel da TMC na construção de significado, na aprendizagem e retenção de vocabulário, na aquisição de línguas e na prática pedagógica do professor de idiomas.

i Assim como Kövecses (2010), Lakoff (2003), Evans e Green (2006) e demais autores adeptos da Linguística Cognitiva, usamos versalete para indicar que aquele sintagma não acontece na língua, mas representa uma metáfora conceptual. Enquanto isso, usamos o itálico para indicar uma expressão linguística metafórica.

ii No original: "The conceptual domain from which we draw metaphorical expressions to understand another conceptual domain is called source domain, while the conceptual domain that is understood this way is the target domain."

iii No original: "Our experiences with the physical world serve as a natural and logical foundation for the comprehension of more abstract domains."

iv No original: "target concepts tended to be more abstract, lacking physical characteristics and therefore more difficult to understand and talk about [...] source domains tended to be more concrete and therefore more readily graspable."

v No original: "abstract thought and reasoning, facilitated by metaphor, are seen as having an imageschematic and hence an embodied basis."

vi Nesse artigo, consideraremos apenas o ensino/aprendizagem de língua inglesa em nossos exemplos e reflexões, por ser a nossa área de atuação acadêmica e profissional. Alguns aspectos poderão ser relevantes ao ensino de outras línguas, tanto estrangeiras como maternas.

vii No original: "An idiom is not just an expression that has a meaning that is somehow special in relation to the meanings of its constituting parts, but it arises from our more general knowledge of the world embodied in our conceptual system. In other words, idioms (or, at least, the majority of them) are conceptual, and not linguistic, in nature."

viii No original: "it makes students aware of the concrete source domains or contexts in which the given words or expressions were originally used in their literal (and thus easily 'imaginable') senses."

\section{REFERÊNCIAS BIBLIOGRÁFICAS}

ALMEIDA, M. L. L.; PINHEIRO, D. O. R.; LEMOS DE SOUZA, J.; NASCIMENTO, M. J. R.; BERNARDO, S. P. "Breve introdução à Linguística Cognitiva". In: ALMEIDA, Maria Lucia Leitão de; PINHEIRO, Diogo Oliveira Ramires; FERREIRA, Rosângela Gomes; LEMOS DE SOUZA, Janderson; GONÇALVES, Carlos Alexandre. (orgs.). Linguística Cognitiva em foco: morfologia e semântica. Rio de Janeiro: Publit, 2010, v. 1, p. 15-50.

BERNARDO, Sandra. "Radialidade das construções de movimento causado presumido Olha só, aqui, ali, lá”. In: Cadernos do CNLF, v. XIII, n. 04, 2009. Disponível em: 
<http://www.filologia.org.br/xiiicnlf/XIII_CNLF_04/radialidade_das_construcoes_de_ movimento_sandra.pdf>. Acesso em: 08 set. 2011.

COSTA, Diógenes Oliveira da. "Fogo e Metal". Dio Costa (blog). Rio de Janeiro, 07 jul. 2011. Disponível em <http://diocostapoemas.blogspot.com/>. Acesso em 10 jul. 2011.

EVANS, Vyvyan; GREEN, Melanie. "Metaphor and metonymy". In:

Cognitive Linguistics: an introduction. Edimburgo: Edinburgh University Press, 2006, p. 286-327.

KÖVECSES, Zoltán. Metaphor: a practical introduction. 2 ed. Nova York: Oxford University Press, 2010.

LAKOFF, George. "Conceptual metaphor: the contemporary theory of metaphor". In: GEERAERTS, Dirk. Cognitive Linguistics: basic readings. Berlim: 2006, p. 185-238.

LAZAR, Gillian. Meanings and Metaphors: activities to practice figurative language. Cambridge, Reino Unido: Cambridge University Press, 2003.

MIRANDA, Neusa Salim. "Domínios conceptuais e projeções entre domínios: uma introdução ao Modelo dos Espaços Mentais". In: Veredas: revista de estudos linguísticos, v. 3, n. 1. Juiz de Fora, 2009, p. 81-95. Disponível em: <http://www.ufjf.br/revistaveredas/files/2009/12/artigo45.pdf >. Acesso em 08 out. 2011.

PINA, Angelina Aparecida de. "Esquema imagético, metáfora e dinâmica de forças: o caso da preposição "contra'". In: Cadernos do CNLF, v. IX, n. 15, 2005. Disponível em: <http://www.filologia.org.br/ixcnlf/15/10.htm>. Acesso em: 03 jul. 2011.

RIBEIRO, Manoel Pinto. Gramática aplicada da língua portuguesa. $17 \mathrm{ed}$. Rio de Janeiro: Metáfora, 2007. 